\title{
Immunohistochemical Characterization of Hepatoblastomas in B6C3F1 Mice Treated with Diethylnitrosamine and Sodium Phenobarbital
}

\author{
Tetsuya SAKAIRI ${ }^{1)}$, Kiyoshi KOBAYASHI ${ }^{1)}$, Kazuhiro GOTO $^{1)}$, Miyoko OKADA ${ }^{1)}$, Manami KUSAKABE ${ }^{1)}$, \\ Takayuki TSUCHIYA $^{1)}$, Jiro SUGIMOTO ${ }^{1)}$, Fumiko SANO ${ }^{1)}$, Mamoru MUTAI ${ }^{1)}$ and Tetsuo MOROHASHI ${ }^{1)}$ \\ ${ }^{1)}$ Toxicology Laboratory, Research Center, Mitsubishi-Tokyo Pharmaceuticals, Inc., 100-5 Yana, Kisarazu, Chiba 292-0812, Japan
}

(Received 9 March 2001/Accepted 29 June 2001)

ABSTRACT. Hepatoblastomas (HBs) were induced in B6C3F1 male mice by diethylnitrosamine (DEN) and sodium phenobarbital (PB). Six-week-old mice received a single intraperitoneal dose of DEN followed by a continuous treatment with PB in diet at a concentration of 0 (group 1) or 500 (group 2) ppm for 50 weeks. HBs were observed in 13 of 21 (62\%) group 2 mice, with typical histologic features as reported previously, while no such tumors were observed in group 1. Seven of 13 (54\%) HBs were found in and/or adjacent to hepatocellular adenomas (HCAs) or hepatocellular carcinomas (HCCs). Immunohistochemically, all HBs were positive for S-100 protein but negative for keratin, $\alpha$-fetoprotein (AFP), albumin (ALB) and vimentin, while HCC cells occasionally reacted positively for AFP with a mosaic pattern. HCC and HCA cells were occasionally positive for ALB. Non-neoplastic hepatocytes and normal bile ducts were positively stained for ALB and keratin/S-100 protein, respectively. S-100 protein is known to be expressed in many mesenchymal tissues and neoplasms including neuroectodermal elements but negative in cells of the hepatic lineage. Thus, the present immunohistochemical results suggested that mesenchymal differentiation occurs in mouse HB cells as observed in human HBs, one of the most frequent infant liver tumors in humans. Although the susceptibility of mouse HBs to PB-promotion suggests a hepatocytic histogenesis, the present immunohistochemical results support the hypothesis that the mouse HB is derived from pluripotent endodermal stem-like cells. KEY WORDS: hepatoblastoma, immunohistochemistry, mouse, S-100 protein.

J. Vet. Med. Sci. 63(10): 1121-1125, 2001

Mouse hepatoblastomas (HBs) are rare, but occur spontaneously in aged animals or can be induced by certain chemicals in some strains $[6,7,10,19,32]$. Histologically, mouse HBs are well demarcated from surrounding normal tissues or hepatocellular neoplasms. In man, HBs are classified into several histological types and differentiation into various components is observed [1, 13, 26, 33]. Mouse HBs, however, lack a variety of subtypes and are histologically less differentiated. Previous immunohistochemical examination of the tumors revealed frequently positive for keratin, but no other specific immunoreactivity has been demonstrated so far $[12,19]$. Although several pathways can be conceived in the development of mouse HBs, no clear answer has been available so far due to their poorly differentiation.

In the present study, we successfully produced HBs at a high rate in $\mathrm{B} 6 \mathrm{C} 3 \mathrm{~F} 1$ mice which received a single dose of diethylnitrosamine (DEN) followed by a continuous dietary treatment with sodium phenobarbital (PB), a well known promoter of hepatocellular tumors in rodents [22], and made a comparative immunohistochemical examination of mouse $\mathrm{HBs}$, hepatocellular adenomas (HCAs) and carcinomas (HCCs) in an attempt to cast light on the histogenesis of mouse HBs.

\section{MATERIALS AND METHODS}

Male 5-week-old B6C3F1 mice were purchased from Charles Liver Japan Inc. (Kanagawa, Japan) and acclimatized for 1 week in an air-conditioned animal room at $22^{\circ} \mathrm{C}$ with a $12 \mathrm{hr}$ light/12 hr dark cycle. Mice were randomized into 2 groups of 10 (group 1) and 24 (group 2) animals. They were fed basal powdered diet and tap water ad libitum. All mice were intraperitoneally administered a single dose of $80 \mathrm{mg} / \mathrm{kg}$ DEN (Tokyo Kasei Co., Ltd., Tokyo, Japan) at 6 weeks of age. Then, they were maintained on a diet containing PB (Tokyo Kasei Co., Ltd.) at a concentration of 0 (group 1) or 500 (group 2) ppm for 50 weeks. At termination, all surviving animals were on euthanasia under ether anesthesia.

Livers were fixed in $10 \%$ neutral-buffered formalin, embedded in paraffin, cut in 3-4 $\mu \mathrm{m}$ sections and stained with hematoxylin-eosin (HE). They were also examined immunohistochemically for keratin, S-100 protein, $\alpha$-fetoprotein (AFP), albumin (ALB) and vimentin. The primary antibodies used were as follows: rabbit anti-keratin, predominantly of 56 and 64 kilodaltons, (ready to use; Dako Japan Co., Ltd., Kyoto, Japan), rabbit anti-S-100 protein (1:400 dilution; Dako Japan Co., Ltd.), rabbit anti-mouse AFP (1:1000 dilution; ICN Biomedicals Inc., Costa Mesa, CA, U.S.A.), goat anti-mouse ALB (1:1000 dilution; Bethyl Laboratories Inc., Montgomery, TX, U.S.A.), and goat antivimentin (1:250 dilution; ICN Biomedicals Inc.). Tissue sections were exposed to these primary antibodies, and then processed by avidin-biotin-peroxidase complex (ABC) methods using Vectastain(r) elite ABC kits (Vector Laboratories Inc., Burlingame, CA, U.S.A.). The sections for keratin or vimentin were incubated with $0.1 \%$ trypsin in phosphate buffered saline for $30 \mathrm{~min}$ before blocking endogenous peroxidase with $3 \% \mathrm{H}_{2} \mathrm{O}_{2}$ in methanol. Visualization of binding was by the peroxidase-diaminobenzidine $(\mathrm{DAB})$ reaction and the sections were counterstained with 
hematoxylin to facilitate microscopic examination.

\section{RESULTS}

Six of the 24 animals in group 2 died or were on euthanasia because of loss of condition. The cause of death or moribundity was ascribed to hepatic tumors because there were no major pathological findings other than the tumors. Three of these mice were excluded from evaluation due to severe autolysis.

Tumors were found only in group 2. The incidences of HCAs, HCCs and HBs were 17/21 (81\%), 13/21 (62\%) and $13 / 21(62 \%)$, respectively (Table 1). All 13 HBs were complicated with HCAs or HCCs. In particular, 7 of them (54\%) were found in and/or adjacent to HCAs or HCCs on the same slides. The others occurred independently. HBs showed typical histologic features as mentioned in previous reports. Namely, most tumor cells were elongated to spindle-shaped with irregular hyperchromatic nuclei and scant basophilic cytoplasm. Between these basophilic tumor cells, nests or rows of $\mathrm{HB}$ cells with moderately abundant eosinophilic cytoplasm were observed. They varied in size and were arranged radially or concentrically around blood vessels, being found as palisading arrangements or ribbons (Fig. 1). HCAs and HCCs also exhibited typical histologic features, the component cells having abundant eosinophilic cytoplasm and large nuclei. HCAs were relatively well demarcated from surrounding parenchyma but with some compression. HCA cells were similar to normal hepatocytes, but cellular atypia were present. HCCs showed highly cellular atypia with trabecular growth patterns (data not shown).

The immunohistochemical findings are summarized in Table 2. All HBs were positive for S-100 protein (Fig. 2) but negative for keratin (Fig. 3), AFP (Fig. 4), ALB and vimentin. The expression of S-100 protein was heterogeneous between the HB cells and strongly positive cells were scattered in the tumor tissues. HB cells in palisading arrangements and ribbons tended to be particularly strongly positive for S-100 protein. On the other hand, all HCCs and HCAs were negative for S-100. HCCs occasionally stained positively for AFP (4/13, 31\%, Fig. 4) with mosaic patterns, but all HCAs were negative. As for ALB, positive cells were sparsely observed in all HCCs and HCAs examined (data not shown). Non-neoplastic hepatocytes were positive for ALB and normal bile ducts were clearly immunoreactive for keratin. The former were negative for S-100 protein while weak staining was seen in the latter. HCAs, HCCs, non-neoplastic hepatocytes and normal bile ducts had no immunoreactivity for vimentin.

\section{DISCUSSION}

Mouse HBs can be induced by certain chemicals in some strains [10, 19]. For example, Diwan et al. [4, 5] reported a high incidence in D2B6F1 mice administered DEN and PB. In the present study, $\mathrm{HBs}$ were induced in $62 \%$ of $\mathrm{B} 6 \mathrm{C} 3 \mathrm{~F} 1$ mice treated with a single dose of DEN and PB in diet for 50 weeks, and this result, including the data for HCAs or HCCs, generally corresponded with the literature.

Human HBs, distinct liver tumors which may occur in infants under 3 years old $[11,13]$, are classified into fetal, embryonal, microtrabecular, and 'small cell' or anaplastic types on the basis of their histological or immunohistochemical characteristics $[1,13,26,33]$. Mouse HBs are histologically similar to the embryonal or 'small cell' types $[4,6]$. In the present immunohistochemical examinations, mouse HBs were found not to react with antibodies against keratin,

Table 1. Incidence of liver tumors

\begin{tabular}{cccccc}
\hline Group & Treatment & $\begin{array}{c}\text { Effective No. } \\
\text { of Animals }\end{array}$ & Hepatoblastoma & $\begin{array}{c}\text { Hepatocellular } \\
\text { Carcinoma }\end{array}$ & $\begin{array}{c}\text { Hepatocellular } \\
\text { Adenoma }\end{array}$ \\
\hline 1 & DEN & 10 & $0(0)$ & $0(0)$ & $0(0)$ \\
2 & DEN+PB & 21 & $13(62)$ & $13(62)$ & $17(81)$ \\
\hline
\end{tabular}

Data shown are the numbers of mice with tumors; incidences as percentages are given in parentheses. DEN: Diethylnitrosamine, PB: Sodium Phenobarbital.

Table 2. Immunohistochemical findings for neoplasms and non-neoplastic liver cells

\begin{tabular}{lccccc}
\hline & S-100 & Keratin & $\alpha$-Fetoprotein & Albumin & Vimetin \\
\hline Hepatoblastomas & $++^{\mathrm{a})}$ & - & - & - & - \\
Hepatocellular Carcinomas & - & - & $+(4 / 13,31 \%)$ & $+^{\mathrm{b})}$ & - \\
Hepatocellular Adenomas & - & - & - & $++^{\mathrm{b})}$ & - \\
Non-Neoplastic Hepatocytes & - & - & - & + & - \\
Normal Bile Ducts & + & ++ & - & - & - \\
\hline
\end{tabular}

( ): Incidence of positive cases.

a) Positive cells were scattered mainly in areas arranged in ribbons or rows.

b) Positive cells were sparsely observed. 

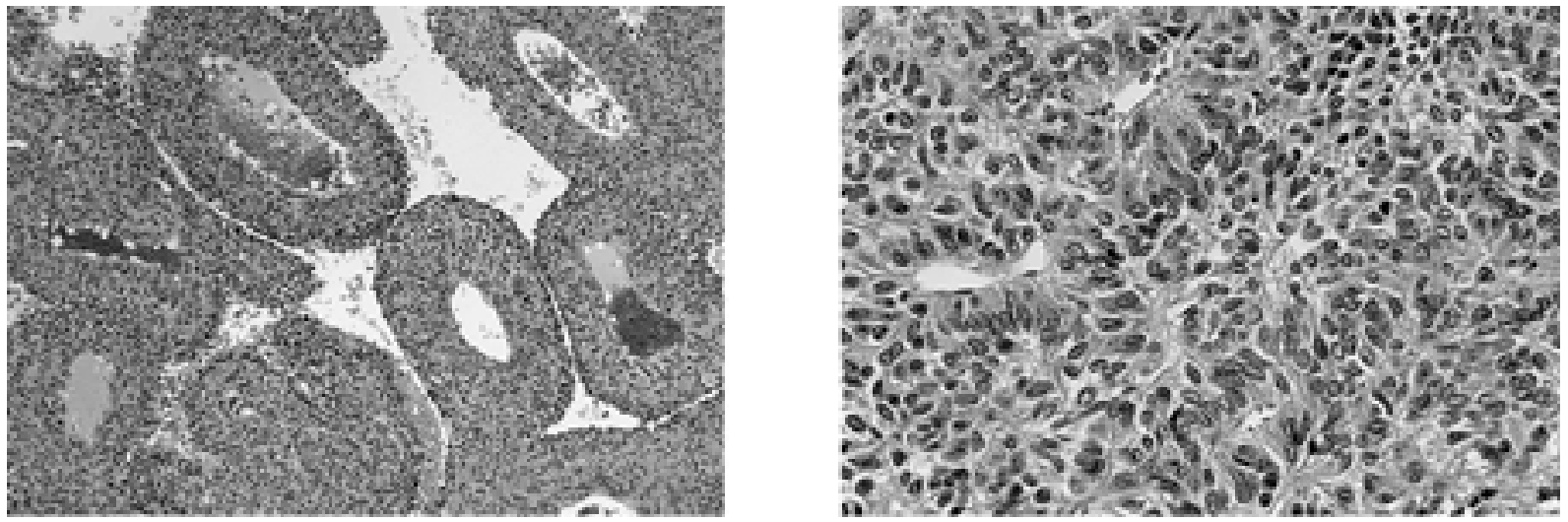

Fig. 1. Hepatoblastoma. Left: Hepatoblastoma tumor cells are radially arranged around blood vessels. HE, $\times$ 55. Right: Tumor cells are elongated to spindle-shaped with scant basophilic cytoplasm. They are often arranged in ribbons or rows palisading around vascular space. HE, $\times 210$.

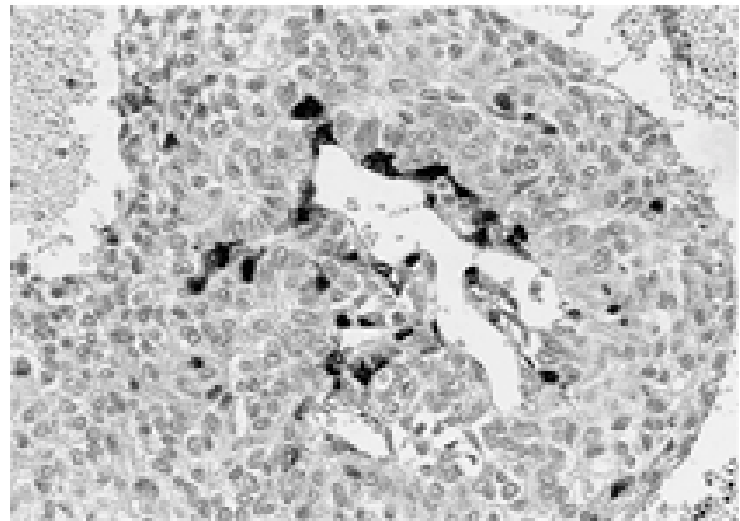

Fig. 2. Immunohistochemical staining for S-100 protein. S100 positive tumor cells were scattered, mainly in an area of palisading arrangement. $\times 220$.

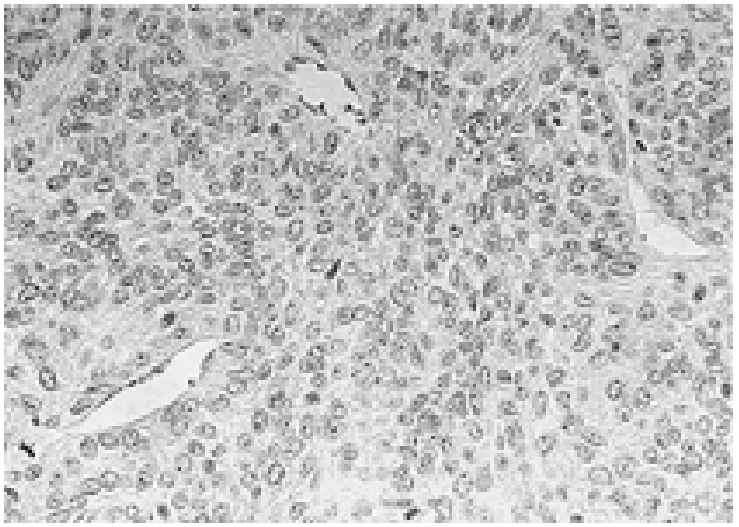

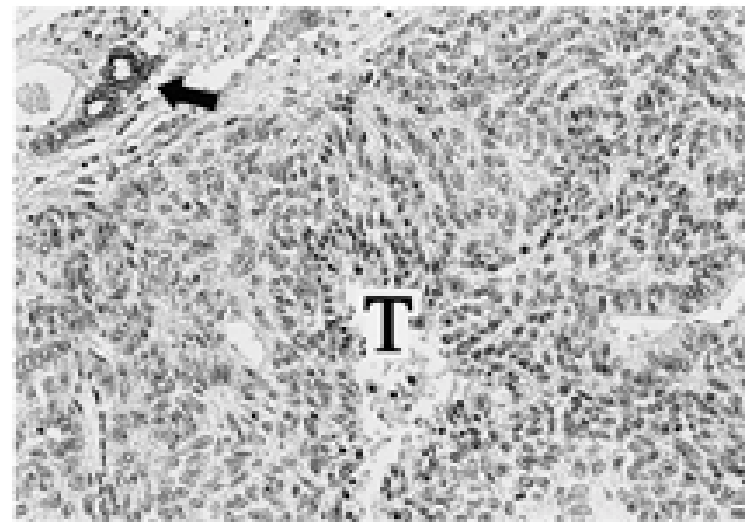

Fig. 3. Immunohistochemical staining for keratin. Hepatoblastoma cells $(\mathrm{T})$ are negative for keratin while a normal bile duct (arrow) stains positively. $\times 110$.

Fig. 4. Immunohistochemical staining for $\alpha$-fetoprotein (AFP). Hepatoblastoma cells are negative for AFP (left) while hepatocellular carcinoma cells are positive, demonstrating a mosaic pattern (right). $\times 220$.

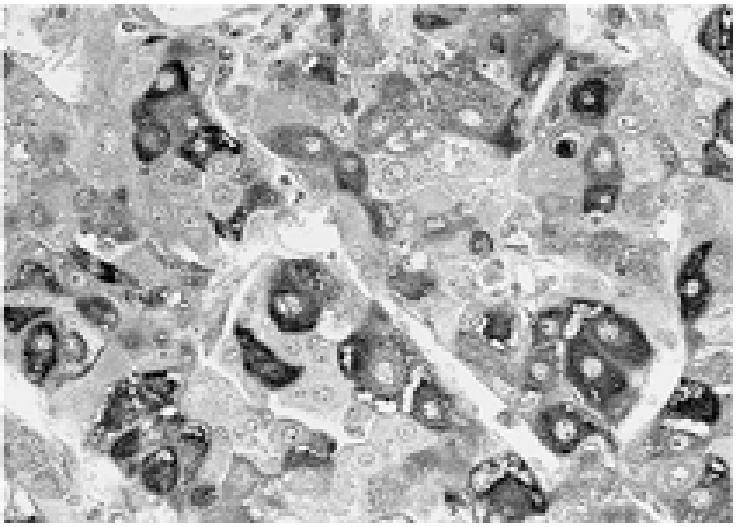


AFP, ALB or vimentin. Nonoyama et al. [19] earlier reported 7 of 16 mouse HBs with squamous metaplasia to show positive reactions for keratin. Differentiation into ductal structures has also been described $[12,20]$. In man, it is considered that the 'small cell' type $\mathrm{HB}$, positive for low molecular-weight keratin, differentiates into the embryonal or fetal type. Some of them become to express high molecular-weight keratin [1]. The reason for the discrepancy with the present results remains unclear, but the negativity of our mouse HBs for keratin, predominantly of higher molecularweight, might point to their being less-differentiated.

Unlike to human HBs which are observed only in infancy or childhood, mouse HBs are usually observed at the latestage of chemical hepatocarcinogenesis studies and seem to grow later than HCAs or HCCs $[3,5,19,32]$. In this study, nearly half of HBs were observed in and/or adjacent to HCAs or HCCs, in line with the previous reports suggesting an origin from hepatocellular lineage. In this context, it is important that HCAs, HCCs and HBs were all observed only in PB-treated mice in this study. It is reported that PB is a mitoinhibitor of DNA synthesis in normal hepatocytes, but promotes growth of initiated hepatocytes or neoplastic cells [18, 22, 29, 34], again suggesting that the origin or precursor of HBs might be identical to that of hepatocellular tumors, susceptible to the promoting effects of PB.

However, one of the most important findings in this study was the immunoreactivity of HB cells for S-100 protein, a mesenchymal marker, in clear contrast to the negative results for HCCs, HCAs, and normal hepatocytes. To our knowledge, this is the first report describing positive reactions of mouse $\mathrm{HB}$ cells for S-100 protein. It is, however, in line with the previous observations in human for HCCs with sarcomatoid differentiation [16, 21] and HBs [17, 25, 36] which were positive for neuron-specific enolase (NSE) and S-100 protein. Shiga et al. [27] reported a HB in a dog to be positive for NSE, but no neuroendocrine granules were observed on electron microscopic examination. S-100 protein is known to be expressed in many neuroectodermal tissues or neoplasms, as well as various other mesenchymal tissues/tumors [2, 9, 15, 35]. Since, in the present study, mouse HBs were negative for vimentin and there are no studies with immunoreactivity for NSE and electron microscopic features, the significance of the S-100 protein expression remains unclear.

Nonoyama et al. [19] previously reported that mouse HBs were morphologically composed of epithelial and mesenchymal components suggesting an origin from bipotential liver blastema cells. Likewise, multidirectional differentiation of HB cells has been extensively characterized in human cases $[17,25,36]$. Furthermore, we recently reported that a cell line established from one of the mouse HBs obtained in the present study required hepatocyte growth factor for optimal growth and expressed $c$-met, a protooncogene encoding the hepatocyte growth factor receptor, suggesting mouse $\mathrm{HB}$ can possibly originated from an early stage of hepatocellular tumor because of the lack of autonomous growth [14]. Though the existence of hepatic stem cells is still controversial [8, 23, 28, 30, 31], the present results illustrate a possibility of multidirectional differentiating potential in mouse HB cells. As recently speculated for human HBs [26], furthermore, mouse HB cells may provide a potential of endodermal cells or play roles, less committed, as even stem cells [24].

In conclusion, although it is not possible to define exactly the histogenesis of mouse HBs, the present study suggests two possible origins - conversion from de-differentiated hepatocellular tumors and de novo generation from undifferentiated stem cells.

ACKNOWLEDGEMENTS. We thank Ms. Tomomi Ishida-Kanamaru, Ms. Hiroko Ito and Mr. Jun Mochizuki for expert technical assistance.

\section{REFERENCES}

1. Abenoza, P., Manivel, J. C., Wick, M. R., Hagen, K. and Dehner, L. P. 1987. Hepatoblastoma: an immunohistochemical and ultrastructural study. Hum. Pathol. 18: 1025-1035.

2. Bonnin, J. M. and Rubinstein, L. J. 1984. Immunohistochemistry of central nervous system tumors. Its contributions to neurosurgical diagnosis. J. Neurosurg. 60: 1121-1133.

3. Calvert, R. J., Tashiro, Y., Buzard, G. S., Diwan, B. A. and Weghorst, C. M. 1995. Lack of p53 point mutations in chemically induced mouse hepatoblastomas: an end-stage, highly malignant hepatocellular tumor. Cancer Lett. 95: 175-180.

4. Diwan, B. A., Henneman, J. R. and Rice, J. M. 1995. Further evidence for promoter-dependent development of hepatoblastoma in the mouse. Cancer Lett. 89: 29-35.

5. Diwan, B. A., Ward, J. M. and Rice, J. M. 1989. Promotion of malignant 'embryonal' liver tumors by phenobarbital: increased incidence and shortened latency of hepatoblastomas in (DBA/2 x C57BL/6)F1 mice initiated with N-nitrosodiethylamine. Carcinogenesis 10: 1345-1348.

6. Diwan, B. A., Ward, J. M. and Rice, J. M. 1992. Origin and pathology of hepatoblastoma in mice. pp. 71-78. In: The Role of Cell Types in Hepatocarcinogenesis (Sirica, A. E. ed.), CRC Press, Boca Raton, FL.

7. Frith, C. H., Ward, J. M. and Turusov, V. S. 1994. Tumours of the liver. pp. 223-269. In: Pathology of Tumours in Laboratory Animals, Vol. II, Tumours of the Mouse, 2nd ed. (Turusov, V. S. and Mohr, U. eds.), International Agency for Research on Cancer, Lyon.

8. Geisler, A., Stiller, K. and Machnik, G. 1994. The cellular reproduction in physiological and reparative liver regeneration. Exp. Toxicol. Pathol. 46: 247-250.

9. Gough, A. W., Hanna, W., Barsoum, N. J., Moore, J. and Sturgess, J. M. 1986. Morphologic and immunohistochemical features of two spontaneous peripheral nerve tumors in Wistar rats. Vet. Pathol. 23: 68-73.

10. Harada, T., Enomoto, A., Boorman, G. A. and Maronpot, R. R. 1999. Liver and gallbladder. pp. 119-183. In: Pathology of the Mouse (Maronpot, R. R. ed.), Cache River Press, Vienna, IL.

11. Ishak, K. G. and Glunz, P. R. 1967. Hepatoblastoma and hepatocarcinoma in infancy and childhood. Report of 47 cases. Cancer 20: $396-422$.

12. Kharkovskaya, N. A., Svinolupova, S. I., Khrustalev, S. A., Engelhardt, N. V., Kondalenko, V. F., Poltoranina, V. S. and Turusov, V. S. 1990. Transplantable mouse hepatoblastoma: 
histologic, ultrastructural and immunohistochemical study. Exp. Pathol. 40: 283-289.

13. Kiss, A., Szepesi, A., Lotz, G., Nagy, P. and Schaff, Z. 1998. Expression of transforming growth factor- $\alpha$ in hepatoblastoma. Cancer 83: 690-697.

14. Kobayashi, K., Sakairi, T., Goto, K., Tsuchiya, T., Sugimoto, J. and Mutai, M. 2000. Establishment and characterization of a cell line from a chemically-induced mouse hepatoblastoma. $J$. Vet. Med. Sci. 62: 263-267.

15. Ludwin, S. K., Kosek, J. C. and Eng, L. F. 1976. The topographical distribution of S-100 and GFA proteins in the adult rat brain: an immunohistochemical study using horseradish peroxidase-labelled antibodies. J. Comp. Neurol. 165: 197207.

16. Maeda, T., Adachi, E., Kajiyama, K., Takenaka, K., Sugimachi, K. and Tsuneyoshi, M. 1996. Spindle cell hepatocellular carcinoma. A clinicopathologic and immunohistochemical analysis of 15 cases. Cancer 77: 51-57.

17. Manivel, C., Wick, M. R., Abenoza, P. and Dehner, L. P. 1986. Teratoid hepatoblastoma. The nosologic dilemma of solid embryonic neoplasms of childhood. Cancer 57: 2168-2174.

18. Manjeshwar, S., Rao, P. M., Rajalakshmi, S. and Sarma, D. S. 1992. Inhibition of DNA synthesis by phenobarbital in primary cultures of hepatocytes from normal rat liver and from hepatic nodules. Carcinogenesis 13: 2287-2291.

19. Nonoyama, T., Fullerton, F., Reznik, G., Bucci, T. J. and Ward, J. M. 1988. Mouse hepatoblastomas: a histologic, ultrastructural, and immunohistochemical study. Vet. Pathol. 25: 286-296.

20. Nonoyama, T., Reznik, G., Bucci, T. J. and Fullerton, F. 1986. Hepatoblastoma with squamous differentiation in a B6C3F1 mouse. Vet. Pathol. 23: 619-622.

21. Papotti, M., Sambataro, D., Marchesa, P. and Negro, F. 1997. A combined hepatocellular/cholangiocellular carcinoma with sarcomatoid features. Liver 17: 47-52.

22. Pereira, M. A., Klaunig, J. E., Herren Freund, S. L. and Ruch, R. J. 1986. Effect of phenobarbital on the development of liver tumors in juvenile and adult mice. J. Natl. Cancer Inst. 77: 449-452.

23. Ponder, K. P. 1996. Analysis of liver development, regeneration, and carcinogenesis by genetic marking studies. FASEB $J$. 10: 673-682.

24. Potten, C. S. and Loeffler, M. 1990. Stem cells: attributes, cycles, spirals, pitfalls and uncertainties. Lessons for and from the crypt. Development 110: 1001-1020.
25. Ruck, P., Harms, D. and Kaiserling, E. 1990. Neuroendocrine differentiation in hepatoblastoma. An immunohistochemical investigation. Am. J. Surg. Pathol. 14: 847-855.

26. Ruck, P., Xiao, J. C. and Kaiserling, E. 1996. Small epithelial cells and the histogenesis of hepatoblastoma. Electron microscopic, immunoelectron microscopic, and immunohistochemical findings. Am. J. Pathol. 148: 321-329.

27. Shiga, A., Shirota, K., Shida, T., Yamada, T. and Nomura, Y. 1997. Hepatoblastoma in a dog. J. Vet. Med. Sci. 59: 11671170.

28. Shiojiri, N., Imai, H., Goto, S., Ohta, T., Ogawa, K. and Mori, M. 1997. Mosaic pattern of ornithine transcarbamylase expression in spf $^{\text {ash }}$ mouse liver. Am. J. Pathol. 151: 413-421.

29. Tamano, S., Merlino, G. T. and Ward, J. M. 1994. Rapid development of hepatic tumors in transforming growth factor $\alpha$ transgenic mice associated with increased cell proliferation in precancerous hepatocellular lesions initiated by N-nitrosodiethylamine and promoted by phenobarbital. Carcinogenesis 15: $1791-1798$.

30. Tateno, C., Takai-Kajihara, K., Yamasaki, C., Sato, H. and Yoshizato, K. 2000. Heterogeneity of growth potential of adult rat hepatocytes in vitro. Hepatology 31: 65-74.

31. Thorgeirsson, S. S. 1996. Hepatic stem cells in liver regeneration. FASEB J. 10: 1249-1256.

32. Turusov, V. S., Deringer, M. K., Dunn, T. B. and Stewart, H. L. 1973. Malignant mouse-liver tumors resembling human hepatoblastomas. J. Natl. Cancer Inst. 51: 1689-1695.

33. Van Eyken, P., Sciot, R., Callea, F., Ramaekers, F., Schaart, G. and Desmet, V. J. 1990. A cytokeratin-immunohistochemical study of hepatoblastoma. Hum. Pathol. 21: 302-308.

34. Waalkes, M. P. and Ward, J. M. 1989. Induction of hepatic metallothionein in male $\mathrm{B} 6 \mathrm{C} 3 \mathrm{~F} 1$ mice exposed to hepatic tumor promoters: effects of phenobarbital, acetaminophen, sodium barbital, and di(2-ethylhexyl) phthalate. Toxicol. Appl. Pharmacol. 100: 217-226.

35. Walker, V. E., Morgan, K. T., Zimmerman, H. M. and Innes, J. R. M. 1994. Tumours of the central and peripheral nervous system. pp. 731-776. In: Pathology of Tumours in Laboratory Animals, Vol. II, Tumours of the Mouse, 2nd ed. (Turusov, V. S. and Mohr, U. eds.), International Agency for Research on Cancer, Lyon.

36. Warfel, K. A. and Hull, M. T. 1992. Hepatoblastomas: an ultrastructural and immunohistochemical study. Ultrastruct. Pathol. 16: 451-461. 